\title{
Parental Traffic Safeguarding at School Sites: Unequal Risks AND RESPONSIBILITIES ${ }^{1}$
}

\author{
Arlene Tigar McLaren \\ Sylvia PARUSEl
}

Abstract. Scholars recognize the importance of parental chauffeuring in urban environments, but pay remarkably little attention to how parents, as part of everyday, domestic practices, safeguard their children in auto-dominated streets. Based on in-depth, qualitative interviews with parents whose children attend public elementary schools, this exploratory study compares traffic safeguarding experiences on the east and west sides of Vancouver, British Columbia. The analysis shows how social class and gender intersect in three traffic sites: school streetscapes, school entrances, and school traffic safety volunteerism. Utilizing automobility and feminist theories, we argue that urban parental traffic safeguarding is a complex and variegated phenomenon involving unequal risks and responsibilities. Our analysis illustrates the ways in which parental traffic safeguarding is a lynchpin to the automobility system, particularly with respect to its illusion of safety, and how, conversely, this system shapes parenting by constituting traffic safeguarding as part of domestic responsibilities.

Keywords: traffic safeguarding, parents, gender and social class, automobility, risks and responsibilities, school sites

Résumé. Les érudits reconnaissent l'importance de conduire ses enfants dans les milieux urbains, mais accordent probablement très peu d'attention à la manière dont les parents, dans le cadre de leurs pratiques domestiques quotidiennes, protègent leurs enfants dans les rues bondées de voitures. Basée sur des entrevues qualitatives en profondeur de parents dont les enfants fréquentent l'école élémentaire publique, cette étude préliminaire compare les expériences relatives à la protection routière des enfants des côtés est et ouest de Vancouver, en Colombie-Britannique. L'analyse démontre de quelle manière les classes sociales et les sexes se recoupent dans trois zones de circulation : les paysages de rue d'école, les entrées d'école et le bénévolat en matière de sécurité routière.

1. Acknowledgements. Our first thanks go to the participants of our study who generously shared their experiences with us. We are grateful for the Social Sciences and Humanities Research Council of Canada funding of this research. We thank Jim Conley and three anonymous reviewers for their helpful comments on an earlier draft of this paper. 
Au moyen des théories féministes et d'automobilité, nous faisons valoir que la protection parentale dans la circulation urbaine est un phénomène complexe et panaché qui comporte des responsabilités et des risques inégaux. Notre analyse illustre comment la protection routière des parents constitue un élément central du système de l'automobilité, tout particulièrement en ce qui concerne son illusion de sécurité, et comment, réciproquement, ce système façonne le comportement des parents en constituant une protection routière dans le cadre des responsabilités domestiques.

Mots clés : protection routière, parents, sexes et classes sociales, auto mobilité, risques et les responsabilités, emplacement des écoles

\section{INTRODUCTION}

$M$ otor vehicle collisions are a leading cause of childhood death and injury in heavily motorized countries (Oliver and Kohen 2009). ${ }^{2}$ In Canada in 2007 alone, 99 children aged 0-14 died in collisions and 626 were seriously injured (Transport Canada 2010). ${ }^{3}$ Since official statistics include neither unreported collisions and injuries nor near misses, however, the figures fail to reflect the full extent to which motorized traffic threatens children's safety (Hillman et al. 1990; Roberts et al. 1995). Whether children are inside or outside a motor vehicle, the threat to them of traffic in car-saturated streets is almost limitless, requiring parents' (or guardians') intense attention, organization, and vigilance (Parusel and McLaren 2010).

In North American urban environments, children's spatial mobility largely takes place within an automobility system dominated by the private motor vehicle. From the inception of the automobile, traffic safety regimes have sought to protect children by removing them from streets with the purpose of promoting the speed and movement of motor vehicle traffic over the rights of pedestrians (Norton 2008). Though death and injury rates on the roads have generally declined in westernized countries during the past few decades as car ownership and kilometres traveled have risen, the fact remains that road traffic is inherently dangerous (Wegman 2007). According to Adams (1993), roads have not become safer; instead, because parents recognize them as so dangerous, they compensate on behalf of their children by removing them from traffic risks. Despite this insight, scholars have paid remarkably little attention to parents' everyday traffic safety practices.

2. Of the major causes of unintentional injury deaths among Canadian children aged 0-14 years, 1994-2003, motor vehicle collisions were the leading cause at $17 \%$, followed by drowning at $15 \%$ and pedestrian injury at $14 \%$ (Safe Kids Canada 2007).

3. For further statistical analysis of motor vehicle traffic incidents among children in Canada, see Oliver and Kohen (2009) and for British Columbia, see Desapriya et al. (2011). 
This article addresses these issues by comparing parental traffic safeguarding at two public elementary schools in Vancouver, British Columbia. Based primarily on in-depth, qualitative interviews, this study explores the ways in which parents (especially mothers) practice traffic safeguarding at three sites: school streetscapes, school entrances, and school traffic safety volunteerism. Utilizing automobility and feminist theories, we argue that such safeguarding is a complex and variegated phenomenon, which involves unequal risks and responsibilities in specific places. We analyze how these risks and responsibilities are shaped by local material conditions of actual threats to children's traffic safety, within dynamic social and spatial contexts, mediated by parents' cultural and experiential interpretations that accommodate to and resist the automobility system. Our analysis also illustrates the ways in which parental traffic safeguarding is key to understanding automobility and its illusion of safety, and how, conversely, this system shapes parenting by constituting traffic safeguarding as part of domestic labour.

The first section introduces automobility and feminist theories and research that inform this paper. The second section discusses the qualitative methods and comparative social and automobilized contexts of the study. The third section explores three traffic sites that illustrate the similarities and differences in parental traffic safety practices within the context of specific urban environments and social inequalities. The fourth section provides some conclusions.

\section{Automobility, Traffic Safety and Social Inequality}

The theoretical interests of this article draw from the "new mobilities" paradigm. This approach highlights movement as transformative of identities and their spatial, temporal, and sociopolitical contexts and is inherently interdisciplinary in that "the very idea of movement implies both a sociological imagination for spatial matters and a geographic sensitivity to understanding social and cultural processes of movement" (Vannini 2010:112). In this paradigm, streets are not merely spaces of circulation nor "non-places." Instead, they are complex sites of social interaction (Jensen 2009), including traffic safeguarding.

As a powerful form of mobility, the automobile is: "a self-organizing autopoietic, non-linear system that spreads world-wide, and includes cars, car-drivers, roads, petroleum supplies and many novel objects, technologies and signs" (Urry 2004:27). Despite the significance of automobility, few scholars have examined traffic safety within its social and spatial contexts and how they shape everyday parental practices. 
We review several kinds of literature informed by automobility and/or feminist theories that provide building blocks for understanding parental traffic safeguarding practices.

One important body of research indicates that pedestrians' vulnerability to traffic risks is unequally distributed in urban environments. Urban children in socioeconomically disadvantaged areas are far more vulnerable to pedestrian injury than children in advantaged areas (Collins and Kearns 2005; Short and Pinet-Peralta 2010). Recent studies of Metro Vancouver found that adult pedestrian injury sites cluster in specific "hotspots" in socioeconomically deprived neighbourhoods (Schuurman et al. 2009; Lord et al. 2010) and that "sweet-spot" (low pollution, high walkability) neighbourhoods are almost exclusively high-income areas (Marshall et al. 2009). Such research demonstrates that social inequalities of daily mobilities and traffic injuries are located in place, an argument that is central to our examination of parental traffic safeguarding practices.

A second body of literature focuses on the ways in which gender organizes parental responsibilities in everyday life and how mothers generally undertake an unequal and invisible burden of responsibilities (Delphy and Leonard 1992; Fox 2009). Research shows how daily mobility is central to mothering practices, including chauffeuring children (Dowling 2000) and monitoring children's local risk landscapes (particularly regarding the predator) in daily mobility (Murray 2008). Women are largely responsible for the broad range of "carescapes" (the caring that takes place within and outside the domestic sphere), but men are also involved in particular ways (Barker 2011). This research on gender and parental mobility care, however, does not focus on traffic safeguarding. A notable exception is Hillman et al. (1990) who consider the large "escort burden" of parents protecting their children from traffic and the impact that the home-school escorting timetable has on female parents' (or guardians') employment status. Law (1999) theorizes the significance of gender in daily mobility and in so doing highlights: the gendered division of labour and activities; access to resources such as transport technology; subject identities and embodiment; symbolic codes; and built environment. In particular for our purposes, Law (1999:582) argues that the built environment (including the organization of land use and physical layout of roads intersecting with transport technology) forms "a gendered structure within which daily mobility practices are enacted." Her theoretical approach suggests the importance of considering how gender structures public space and specific sites, which we explore in this paper.

A third body of work that contributes to our study focuses on gender and social class relations between parents and schools. Mothers usually 
help with homework, fund raising, and volunteering more than fathers (Levine-Rasky 2009), but less is known about how gender and social class intersect. In their path-breaking research, Griffith and Smith (1987) discuss the ways in which the discursively organized educational system depends on highly resourced, full-time mothers' work, while stigmatizing single mothers' practices that are constrained by their social and economic positions. Other leading studies draw upon Bourdieu's theory of social class to show the advantage that middle-class mothers have over working-class mothers in activating varied forms of capital (including cultural, social, and economic) to engage confidently with the school system (Reay 1998; Lareau 2003). Scholars, however, have paid little attention to how social inequalities interact in shaping parental traffic safeguarding of children en route to and from school and in school volunteerism.

A fourth strand of work critically analyzes the culture and ideology of traffic safety. Moeckli and Lee (2007) call for theorizing culture in driving safety research that attends to everyday practice, the plurality of traffic safety cultures, the contestations between different actors and scales of interaction, the ways in which culture is imbued with power, and the importance of modifying driving culture through changes in social practice. Their discussion delineates a broad, dynamic, and critical approach to culture, which is absent in typical traffic safety discourse.

In their analysis, Freund and Martin (1997) argue that the ideology of automobility restricts discourses about traffic accidents and obscures the systemic features of auto-centred transport. As part of this critical approach, studies show that powerful auto-dominated, legal and cultural discourses hold parents responsible for their children's safety and typically blame them rather than drivers for any mishaps that befall children (Hillman et al. 1990; Jain 2004; Norton 2008). Few studies, however, direct their attention to how in their everyday lives parents actually consider traffic safeguarding. A notable exception is Thomsen's (2005) research on the social construction of parents' worries about traffic risks that are interpreted through perceptions of safety and childhood experiences. Her study, however, is limited by not locating the parents' worries within specific auto-dominated spaces and how they are shaped by social inequalities. Caollins and Kearns (2005) and Collins et al. (2009) examine the walking school bus in Auckland, New Zealand in which volunteers (almost exclusively mothers) walk with groups of children to and from school. The authors show how this strategy serves parents' purposes of promoting children's health, sociability, and traffic safety, and also challenges ingrained assumptions that children must yield to cars. This research reveals a dynamic process in which a parental mobil- 
ity strategy both accommodates to and resists automobility; the strategy, however, includes but one form of parental safeguarding that is mainly adopted in affluent urban areas.

The literature on parental traffic safeguarding is limited not only empirically but also theoretically in relating it to the larger automobility system and traffic safety regime. Beckmann's (2004) argument about the social organization of road accidents provides insight into understanding how the automobility system works by denying the risks of driving. Beckmann contends that by cleaning up roads, repairing cars, healing victims and locking up irresponsible drivers, accident workers create an illusion of safety and promote automobility and the flow of traffic. Similarly, we suggest that, in aiming to prevent collisions in the first place, everyday parental traffic safeguarding practices result in "cleansing" the road of children, which creates the illusion of safety and fosters automobility. Parents free up urban and suburban streets for motor vehicles by, for example, chauffeuring their children in cars (which ironically contributes to traffic), containing them spatially within the confines of sidewalks and homes, and keeping a watchful eye and ready hand to preempt a fateful collision. As a result of parents' relative success in protecting, constraining and disciplining their children's mobility, the everyday risks (as car passengers, pedestrians, etc.) of auto-saturated streets remain largely hidden from social and political discourse. Sleet et al.'s (2007) discussion, which is typical of traffic safety discourse, extols the importance of governments and organizations in changing driver behaviour, vehicle design, and road design that result in greater individual mobility and population safety. The authors do not acknowledge the significance of parents' daily practices that, in curtailing children's vulnerability to traffic, reduce motor vehicle crashes and injuries. More generally, the traffic safety literature does not consider the dynamic contestations between traffic safety cultures, and how parents not only constitute and advance traffic flow but also seek its interruption in negotiations with it.

As a crucial domestic, social practice, parental traffic safeguarding remains under-studied and under-theorized (for further discussion, see McLaren and Parusel, in press). It has become routinized and normalized to such a degree that it fades into the backdrop of the ordinary and unremarkable. Its hidden character not only creates the illusion of safety and denial of risks, but also obscures social inequalities. Parental traffic safeguarding has parallels with other kinds of invisible, domestic work and safekeeping that reflect gender and social class in specific environments (Roberts et al. 1995). This article, which considers the dynamic and unequal risks and responsibilities of parental traffic safeguarding, explores how such practices (e.g. chauffeuring) constitute the automobil- 
ity system and also resist it (e.g. organizing against traffic risks), both promoting and interrupting traffic flow.

\section{Methods, Parents, and Contexts}

The mobility turn in the social sciences distinguishes its approach from such fields as the sociology or geography of transportation that rely heavily on quantitative research. Law (1999) calls for qualitative research on daily mobility that is grounded in specific and differentiated locales, allowing for the investigation of both the lived experiences of individuals as well as their material and cultural contexts. While localized and qualitative approaches are limited in scope and generalizability, they provide rich, in-depth explorations of multilayered everyday practices.

As a preliminary analysis of parental traffic safeguarding, the authors conducted a comparative study of two elementary schools in Vancouver, $\mathrm{BC}^{4}$ that were selected to reflect broad, social class differences. One school is located on the east side (ES school) and the other is on the west side (WS school) of the city. Historically, the east side of Vancouver has been composed of relatively low-income residents and recent immigrants. In contrast, the west side has been composed of relatively highincome residents, still reflecting mainly British heritage but also with recent influxes of wealthy immigrants from such countries as China and Korea. The two schools were also selected purposively for their similarities: located in inner suburbs, with grades kindergarten to seven English (not French Immersion) instruction, approximately the same student population size and traffic counts at nearby major intersections. As inner suburbs, the two school neighbourhoods are approximately the same distance from the central area of the city, but differ socioeconomically, as evidenced in their proportion of single-detached houses. Only about one-quarter of the dwellings in the ES school neighbourhood are singledetached houses, with detached duplexes and apartments in the majority, whereas almost three-quarters of the dwellings in the WS school neighbourhood are single-detached houses (City of Vancouver 2009a).

Between 2007-2009, the study undertook qualitative fieldwork including: participant observation; the collection of local documents; interviews with key informants; and in-depth, semi-structured interviews with parents. This article, which draws upon local documents, informal observations of the school sites and discussion with a key informant who is a school principal, is primarily based on interviews that took place with 10 parents at the ES school and 12 parents at the WS school. Core questions that guided the interviews were: How concerned is your chil-

4. The names of communities, schools and parents have been changed for anonymity. 
dren's school with traffic safety? What are your specific concerns about school traffic safety? How important an issue is traffic safety? What are your concerns about the neighbourhood traffic around your school? All interviews were audio taped and took place in homes, cars, or at the schools. The parents also filled out a brief questionnaire to provide a demographic profile of the sample. To code the individual interviews (on average over an hour long), the focus group interview (over two hours long), and to carry out the preliminary analysis, NVivo software was used.

We recruited parent participants through the schools by attending Parent Advisory Council (PAC) meetings and school events, sending notices home with children, and approaching parents and caregivers at the school entrance. At the WS school, six of the interviewed mothers, who were members of a PAC subcommittee on traffic safety, agreed to participate in a focus group. Despite our efforts, parents at the ES school were not available for a focus group discussion. Altogether 17 mothers and 5 fathers took part in the study: 4 fathers and 6 mothers from the ES school; 1 father and 11 mothers from the WS school. This differential gendered participation echoes the general pattern noted above of mothers being more involved in their children's schooling than fathers, but also suggests social class differences that we explore below. Parent participants at the ES school were generally younger (ranging in age from 24-44) than parents at the WS school (ranging in age from 34-50). At the ES school, parent participants had from 1-4 children; of the children who attended the school, half were aged 5-8 years old; the other half were aged 9-12 years old. At the WS school, parent participants had 2 or 3 children; the distribution of ages of the children who attended the school were similar to the ES school: half were aged 5-8 years old; the other half were aged 9-12 years old.

While the parents who agreed to participate in the study may have been particularly concerned about traffic safety, the sampling generated a wide range of social characteristics of parents within schools and marked differences between the schools that reflect their neighbourhoods. Parents at the ES school reported annual family incomes ranging from under $\$ 30,000$ up to $\$ 70,000$. One mother was unemployed; the others had fulltime or part-time jobs. Four participants reported that they were single parents. Five parents self-identified as Caucasian or Canadian-European; the other five identified as Aboriginal, Asian, Chinese, Filipino, or Mexican. In contrast, parent participants at the WS school reported annual family incomes ranging from $\$ 50,000-\$ 130,000$. None indicated that they were a single parent. Five reported that they were a "stay at home" mother or a volunteer; the others had part-time or full-time employment. 
Nine self-identified as Caucasian, one as Chinese (two did not fill out the questionnaire sheet).

The distinct profiles of parent participants reflect their schools and school neighbourhoods. The ES school has a higher proportion of ESL (English as a Second Language), Aboriginal, and special needs students, and families with low income than the Vancouver school district average (BC Ministry of Education 2009). Indeed, the ES school came close to being designated an "inner city" school by the Vancouver School Board for extra funds and programs (ES school principal). Relative to Vancouver as a whole, the ES school community has above average low-income households, unemployment, single-parent families, and a substantially higher population whose mother tongue is not English (City of Vancouver 2009a).

In contrast, the WS school has a lower proportion of ESL students than the ES school (but higher than the school district average). As well, the WS school has a lower proportion of Aboriginal students, though similar proportion of special needs students, and lower proportion of low-income families than the Vancouver school district average (BC Ministry of Education 2009). Relative to the city as a whole, the WS school community has below average low-income households, unemployment, single-parent families, and a substantially lower population whose mother tongue is not English (City of Vancouver 2009a). These social characteristics, which distinguish the two schools, the parent study participants, and the school neighbourhoods, indicate broadly different contexts of parental traffic safeguarding related to social class, gender, family structure, labour market participation, and ethnicity.

In addition, mobility patterns provide a context for comparing the two school neighbourhoods and parents' concerns about traffic. In the two inner suburbs, especially in the west side community, the proportion of people who drove a motor vehicle to work was above the Vancouver average of 52\% (City of Vancouver 2009a). This pattern echoes research which shows that car dependency in Canada generally increases with distance from city centres (Turcotte 2008). The fact that the east side community was above the Vancouver average in driving motor vehicles to work is consistent with US findings that auto ownership is high even among the poorest households, where the car is the primary mode of travel (McMillan 2005). In the east side community, however, residents were more likely to take public transit than Vancouver as a whole (25\%) and more than twice as likely as residents in the west side community. In contrast, the percentage of those in the west side community who walked or biked to work was considerably higher than residents in the east side community (City of Vancouver 2009a). 
Particularly germane to our study is the mapping of the "most dangerous intersections" for traffic crashes between 2005-2009 in Vancouver neighbourhoods (Skelton 2010) which reveals that they are concentrated on the east side of the city. Within the ES school catchment area, the map identifies about 10 worst intersections and over 2000 crashes. In contrast, within the WS school boundaries, the map identifies less than one-quarter of the worst intersections of the ES school area and less than one-quarter of crashes, demonstrating that traffic is considerably more dangerous in the ES school neighbourhood. On the other hand, since crashes occur regularly at the same Vancouver intersections year after year, the data also indicate that the traffic in both school catchment areas is predictably and inherently dangerous for children's journeys to and from school.

\section{Parental Traffic Safeguarding at School Sites}

A trip diary survey of Metro Vancouver indicated that in 1984 30\% of children (grades kindergarten to 12) traveled to school by car. Ten years later, the percentage had risen to $45 \%$ without significant change since then (City of Vancouver 2002). Many factors affect children's travel mode to school, which include the built environment, social influences such as the car culture, and parents' perceptions of safety and danger (Ridgewell et al. 2009). While the trend of increased parental chauffeuring in the school journey is well documented (for example, Pooley et al. 2005), little research has considered how parents practice traffic safety in their various modes of travel. Most families in our study used several kinds of transportation between home and school. If they drove a car, they often incorporated other forms of mobility, for example: driving close to the school, then walking the rest of the way; driving a younger child, but not an older child to school; or never driving a child in the morning but always in the afternoon to reach a tutoring appointment on time. The interviewed parents provided detailed and contextualized portrayals of their traffic safety concerns based on a variety of daily mobility experiences (by car, on foot, or bicycle and whether or not children were chauffeured, escorted, or unescorted).

To explore parental traffic safeguarding practices, we analyzed traffic sites that parents identified as particularly troubling: school streetscapes, school entrances, and school traffic safety volunteerism. While parent participants at the ES and WS schools shared many of the same fears about traffic in their children's school journey, their discussions vividly brought into view unequal forms of risks and responsibilities. In particu- 
lar, parents at the ES school were worried mostly about the nonparental traffic traveling through the school streetscape whereas the WS school parents were especially anxious about the parental traffic converging at the school entrance during peak drop off and pick up times. This latter site was a highly contested space particularly between different kinds of mothering mobilities and traffic safeguarding practices. It is a site that reveals the complex ways in which parenting constitutes automobility and resists it, especially in the form of parental volunteerism at the WS school. As the analysis moves from school streetscapes to entrances and to traffic safety volunteerism, it explores how gender and social class intersect in different spaces of traffic and parental safeguarding practices.

\section{School Streetscapes}

Since Vancouver residents rely significantly on motor vehicles for transportation, it is no surprise that both schools are located next to busy arterial roads, which parents and children negotiate in the school journey. ES school parents emphasized that the local streetscape, which includes a high volume of speeding traffic and heavy commercial trucks leading to a major highway, was especially menacing. Even with such safety measures in place as traffic lights, crosswalks, and reduced speed limits, the parents and children could not count on them for protection. Besides the greater presence of heavy trucks, the local streetscape differs from the WS school in having less green space - fewer large trees, sidewalk boulevards and parks - that separate nonmotorized from motorized mobilities.

Christina, who had children aged five and seven, indicated that nonparental, rather than parental traffic, was the main issue of concern at the ES school: "I think the biggest issue is the cars that are sometimes racing by on either side of the school. So, it's not necessarily the parents, but we're often a shortcut to the highway." She elaborated that the school's location has a high "energy level" of truck traffic:

We're just bounded by two very busy roadways that have big trucks. It's not just cars, it's these big trucks just going quickly. And sometimes just not stopping, you know ... just, the energy level — suddenly you're just having to really be aware of crossing the street.

Other parents concurred. Manuel who had children aged six, nine, and twelve, explained:

The trucks ... they go uphill there, and there's a light, so the trucks try to gain speed and then when this light goes red, they cannot stop right away, because they're heavy trucks, so it's, I think it's a problem here. 
Parents at the ES school expressed wariness about letting their children walk or bike to and from school by themselves, even as they became older. For example, Kerry, who had children aged five and ten, said:

It's just so hard to just be able to let them just go. You know, across the street by themselves ... you're just feeling like okay, if they didn't just watch that one time, ... you're always going to put yourself there, like, if I was there, that wouldn't have happened ... everything is just scary about it.

The parents' remarks recall research indicating that children are at a higher risk of traffic injuries in more socially disadvantaged than socially advantaged neighbourhoods due to high traffic volume and speeds, and lack of safe pedestrian crossings and outdoor play areas (Laflamme et al. 2010). However, such studies do not adequately take into account the impact of truck traffic in which weight and speed combine to create an especially high-risk environment for road users (Mayhew et al. 2004). The truck routes, which dissect the ES school neighbourhood, reflect a general pattern in Vancouver of more truck routes existing on the east than west side of the city, ${ }^{5}$ creating unequal traffic risks and responsibilities for parents.

In contrast, the WS school is located in a neighbourhood with more green space and far less truck traffic. Interviewed parents considered the school neighbourhood to be relatively walkable and safe, suggesting why residents in the WS community have a higher rate of walking and bicycling than those in the ES community. For instance Annette, who had children aged six and nine and often walked with them through the park to the school, stated: "It's a very safe neighbourhood and, you know, kids are out in the street a fair bit." Narratives of walking places, Bean et al. (2008:2844) found, distinguished them as "local, safe, aesthetically pleasing and separated from busy traffic."

But WS school parents also talked about threatening roads and intersections in the school vicinity. Kate, who had children aged five and seven, referred to an intersection close to the school where a crash occurred (ironically involving a truck):

Top of the hill ... with speed, people come down; it's unbelievable ... about a month ago there was a nasty accident there between a car and truck.... And I think just within my group of friends ... we're kind of thinking ahead of, you know, one day they're going to want to walk to school, with a group of them, and no I don't feel safe.

Despite the dangers of this intersection - designated as one of the worst intersections in Vancouver because of repeated crashes (see discus-

5. Historically, Main Street has divided the east and west sides of Vancouver. Truck routes predominate on the east side of the city (see City of Vancouver (2009b) truck route map). 
sion above) - the City was unwilling to implement a crosswalk or traffic light. Nicole (who has an infant and children aged 5 and 8) said: "I've been regularly requesting a crosswalk at that spot from the City. And they study it and they say, 'There's not enough people to warrant it'."

This unfulfilled request illustrates the ways in which traffic safety is a strongly contested issue involving multiple actors with differential power (Moeckli and Lee 2007), and how parents resisted automobility and sought to interrupt traffic flow. A few years ago, parents at each of the schools supported petitions for a pedestrian-controlled crosswalk in the neighbourhood; crosswalks were eventually installed in both cases. Nonetheless, traffic safety infrastructure at the schools (e.g., marked crosswalks or traffic lights at busy intersections; speed humps to slow down traffic) remains minimal and far from satisfactory to the parents and the school staff whom we interviewed. The desire for safer school streetscapes was a constant theme that pitted parents against such public authorities as the provincial education ministry, city government, school board, and police. Drawing from an ideology of automobility, these governing bodies held parents primarily responsible for safeguarding their children from traffic and discounted parents' and school staff's everyday experience and knowledge of the traffic risks around schools (Parusel and McLaren 2010). Nicole's statement that the City did not believe there were "enough people" to warrant a crosswalk or light at the intersection speaks to the gaps - of experience, consultation, communication, and representation - in transport policymakers' top down approach and disregard for local needs, which is compounded by the gender-bias of the transport planning profession (Rajé 2007). Local authorities did not attend to the voices of parents (notably mothers who were more involved in traffic safeguarding than fathers) and yet in our interviews it was evident that they were well informed about the quality of the traffic risks in the school neighbourhood. The differential power of traffic safety experts (and administrative bodies) vis-à-vis parents raises questions for future research about how the ideology of automobility combines with spatial and social inequalities to discursively deny the significance of parental concerns about traffic risks while considering parents to be responsible for safeguarding children to enable traffic flow.

This preliminary investigation of school streetscapes suggests that parental traffic safeguarding suffers not only from the ideology of automobility that promotes private motor vehicle dominance on public roads over other interests, but also from social class inequality in which the dominance is imposed more strongly in some city neighbourhoods than others. In the largely working class ES school neighbourhood, parents felt particularly exposed to dangers of nonparental traffic, especially the 
heavy trucks that pass through the school area. The automobilized context created an unnerving and never-ending demand that parents protect their children and gave them little reason to trust the traffic safety measures that were in place. At first glance, traffic in the school streetscapes does not appear to be gendered, but in distinguishing between nonparental (especially the heavy commercial trucks) and parental traffic, the gendered structure of the roads becomes apparent. Driving, which has long been associated with hegemonic masculinities but increasingly with new forms of femininities (Lupton 1999), remains highly masculinized in the trucking industry (McLean 2010). This gendered industry creates an excessively high-risk environment for road users that reflects its organizational practices. Dispatched trucks "represent corporate needs, management-labour relations, blue-collar workers toiling for pay, company profits, breaches of laws and regulations, and the construction of highrisk traffic scenarios" (Rothe 2002:143). In addition, trucking is the only commercial freight mode in Canada that is not regulated at the federal level for safety (MacGregor 2002). Male domination of public spaces as a reason for women's fears and strategies of curtailing their movements is well established in the criminology literature (Stanko 1997). But as Law (1999:583) contends, the time is ripe for "new ways of thinking about transport-related issues as a gendered set of practices and meaning." Our research raises questions about the gender-coded structure of the trucking transportation system and how its physical presence on urban roads draws upon male entitlement to control specific kinds of public space and ride roughshod over and subordinate other forms of mobility. Freund and Martin (1997) note that auto-centred transport systems seem to have in mind forty-year-old healthy males driving cars. It is time to analyze the extent to which the trucking industry represents particular forms of masculine corporate cultures and claims to urban roads that contribute to unequal parental/mothering risks and responsibilities in safeguarding their children from traffic.

The masculinized, nonparental traffic in the ES school journey contrasts to the feminized, parental traffic at the WS school. Though parent participants at the WS school were anxious about the local streetscape, which involved both nonparental (but rarely heavy trucks) and parental drivers, they reserved their greatest concerns for the chaotic and congested parental/guardian traffic that converged at the school entrance.

\section{School Entrances}

As chauffeurs or escorts, parents often experienced school entrance chaos and congestion at first hand during peak drop off and pick up 
times. At this site, drivers - including sometimes grandparents, friends, nannies, etc. — regularly flouted traffic safety rules, including: U-turns; stopping at "no stopping" zones; parking at "no parking" zones; double parking; speeding above the posted school limit; or zipping around corners without due attention.

Several parents at the ES school talked about the chaotic entrance. For example, Susan, who had children aged six, eight, and nine and chauffeured them to school about twice a week, noted the irony of talking about school traffic safety:

We don't practice traffic safety. [Laughing]. That's not funny.... We have U-turns in the middle of [the street]. And, you know, double parking of cars when people are picking up and dropping off their kids, and cars backing up in the driveway and turning.

Note the "we" in her remarks that suggest the contradictory positioning of parents as errant drivers and safety guardians. During an interview in the car with Tom (who had children aged eight and nine and chauffeured them to school about twice a week), a U-turn was observed:

SP: What's this person doing? [car drives by and tries to make a U-turn]

Tom: Backing up - making an illegal U-turn.

SP: Hey, yeah.

At the WS school entrance, however, the congestion and chaos was especially evident. Before the bell, fleets of cars converge onto the street that runs alongside the school. As drivers jostle with one another to find a space to stop, parents and children who cross the street on foot are forced to negotiate the unpredictable traffic. Gillian (who chauffeured her two younger children, aged six and seven, several times a week while allowing her older child, aged 10, to walk alone) stressed the close calls that happen during drop off and pick up time: "Parents are in a hurry to drop off their kids and so they're not looking ... even with the lighted crosswalk, cars turning left or right, again not yielding to the pedestrian that's walking. Yeah. So close calls." Other parent participants at the WS school shared Gillian's worry that traffic safety infrastructure such as a lighted crosswalk did not protect children at the school entrance. These parents' concerns about the inadequacy of traffic safety infrastructure in protecting children were similar to ES school parents', but with an emphasis on parental rather than nonparental traffic.

A strong, local culture of mothers chauffeuring their children was apparent at the WS school, which resonates with a growing body of literature about how powerful expectations of good mothering include 
car use to care for children (Dowling 2000; Barker 2011). Nonetheless at this school, mothers had also developed a significant walking/biking culture (accompanying their children or allowing their children to walk or bike unescorted). Whether the practices involved driving or walking/ bicycling, women had more responsibility than men, and as underscored by Lisa, had more experience and knowledge about traffic safeguarding: "Husbands sometimes, you know, they don't walk the kids to school, they don't know what's going on, safety-wise at the school."

The highly feminized parental culture at the WS school entrance indicates longstanding gender inequities in domestic labour but also reflects complex interactions with social class. For example, some WS school mothers in our study had elevated family incomes that allowed them to be full-time mothers and to engage in school activities, including chauffeuring or escorting children to protect them from traffic. Our observations also suggest that some men chauffeured and escorted children to and from school providing evidence of shared responsibilities in families. The gender disparity of more women than men chauffeuring and escorting children at the WS school was less obvious at the ES school. In the next section, we explore further the mothering culture that was institutionalized in the WS school's parent-run traffic safety program and absent at the ES school.

\section{School Traffic Safety Volunteerism}

The WS school entrance was a site that revealed the multiple mobility positions of mothers, their clashes with one another over safeguarding, and the diverse ways that they constituted automobility and resisted it. Interviewed parents (almost all mothers) at the WS school straddled various, and often conflicting, mobility and safeguarding positions in the school journey that ranged from monitoring their children's mobility from home, to escorting and chauffeuring, to resisting the local car culture by volunteering in the school's traffic safety program. As a spatial site, school traffic safety volunteerism existed in various places (e.g., monitoring the school entrance, attending meetings, and developing travel surveys). The WS school had a highly organized Parent Advisory Council (PAC), in which a large pool of parents, particularly mothers, attended PAC meetings and volunteered to help with school activities, including a subcommittee of mothers who actively promoted school traffic safety programs. Gillian, the WS school traffic safety coordinator, organized safety procedures at the beginning and end of each school day (e.g., traffic cones and a sandwich board to designate drop off and pick up areas). In addition, the subcommittee promoted alternative travel to 
school, which included developing classroom travel surveys and school gate navigation instructions to participate in the annual International Walk to School Week.

While the WS school traffic safety program benefited from having mothers who were available to volunteer, their participation was fraught with difficulties due to frustration, fatigue, employment and family demands, changing priorities with older children, or moves to other schools. For example, mothers in the focus group talked about the conflicts they had had with chauffeuring parents who flout the traffic rules at the school entrance, and how unpleasant "confrontational volunteerism" is, with its lack of authority:

Valerie: So many people just won't listen to just another parent ... there's this idea that "who are you to tell me what to do?"

Rachel: "Who are you with too much time on your hands?" [laughter]

After Gillian left the position as traffic safety coordinator in June 2008, it remained unfilled the following year.

Though interviewed ES school parents were equally concerned about protecting their children from traffic, school volunteerism was less developed at their school than at the WS school. Despite the principal's efforts, the ES school had only a rudimentary structure of traffic safety. Occasionally a few parents and the principal monitored the school entrance traffic. The school did not participate in alternative mobility promotions such as Walk to School Week, and though in 2007/2008 three staff volunteers spearheaded a traffic safety committee at the school, a year later it still lacked both a budget and parent members.

The reasons for this difference in parental volunteerism between the two schools are manifold. First, gender, family structure, and social class intersected to prohibit women's engagement in school activities at the ES school. Their employment routines conflicted with institutional gendered discourses about mothers volunteering in school programs. During recruitment for the study, many mothers as well as fathers indicated that they could not participate because of work schedules and in interviews several said their shift work's inflexible hours prevented school involvement. ES school mothers whom we interviewed were all employed (one was looking for a job) and three were single mothers. Due to multiple structural constraints, they had no time to be involved with school traffic safety programs. Kerry, a single mother of two children said:

It would be good, but like, if I had more time, some time on my hands, I'd want to be more involved in the school ... but I like, I'm a single parent so I'm working, like, all the time.... Working full time, and yeah, so, 
yeah, I like have very, very, minimal time on my hands. Most of the time working six days a week and on weekends and stuff. Oh yeah. So, I try my best [laughs].

Susan, a married mother with three children and a part-time job, tried to organize parents to monitor the ES school entrance, but was unable to run the program: "You've got three or four of us that are really gungho and want to do it. But it can't run with three or four people." She explained that most parents have other commitments and some rely on grandparents: “They're busy; you know people are busy. They've got things to go and do, they're working or in the case here, a lot of kids are going home with their grandparents." The disparity in volunteerism between the two schools echoes research on the walking school bus initiative in Auckland, New Zealand, which rarely exists in socially deprived neighbourhoods, with the possible impediments to voluntarism being parents' poverty, ill health, or employment routines (Collins and Kearns 2005). Second, the ES school parents had fewer resources such as the help of a nanny (as in two cases of the WS parent participants) or economic and cultural capital to enable greater school involvement. As has been widely discussed in the literature on schooling and cultural capital (e.g., Lareau 2003; Reay 1998), families that are unfamiliar with speaking English or with the workings of the educational system are less able to actualize their concerns about school affairs. Third, governing bodies (e.g., the school board, municipal, provincial, or national governments) do not provide adequate funds and support for schools to develop and maintain traditional traffic safety programs to offset the limited time and resources of parents (Parusel and McLaren 2010). Finally due to the ideology of auto-centred transportation, parental traffic safety programs established in schools focus primarily on the entrance, which was of secondary importance to interviewed ES school parents. They were mainly worried about the dangerous local streetscape of truck routes. Alternative discourses and practices that would reflect the parents' knowledge and experience and seek to overcome this dangerous and unruly school streetscape were not readily available for mobilization.

As a result of parents and school staff having to fend for themselves to develop traffic safety programs, major disparities and contradictions existed between the two schools in the ways that gender and social class interacted and in the consequences for school traffic safeguarding. Parental responsibility for developing traffic safeguarding programs depended on parents' (mostly mothers') availability to participate in school activities, which led to the traffic safety program advantage of the WS school. Even so, educational and municipal governing bodies failed to 
give mothers the recognition and support they sought (such as improvement in traffic safety infrastructure, greater authority for promoting driver cooperation at the school entrance and funding for initiatives). Programs were ad hoc and unstable from year to year, illustrating the fluidity of mothers' involvement in school traffic safety volunteerism, even in the well off neighbourhood. The differences between parental participation in the two schools' traffic safety programs suggests that future studies need to examine the distinct traffic risks in school neighbourhoods, how they are embedded in social and spatial inequalities and the kinds of institutional supports and transformations needed by schools and parents to overcome them.

\section{Conclusion}

While scholars recognize the significance of parental chauffeuring, few studies focus on how urban parents safeguard children in auto-dominated streets. Our comparative case study of two schools in Vancouver, British Columbia brings into view parents' differing and overlapping practices of traffic safeguarding children at the three school sites of streetscapes, entrances, and volunteerism. At the relatively working class ES school, interviewed parents identified nonparental truck traffic on local streetscapes as especially dangerous. Parents underscored their anxieties that, even with such safety measures as traffic lights, crosswalks, or reduced speed limits in place, they and their children could not count on them for protection. The parents' views about nonparental traffic suggest the need for scholarship to consider how the masculinized trucking industry dominates specific urban areas, how such spaces are shaped by gender and social class, and how traffic safety infrastructure supports this industry. Roads that cater to heavy, commercial trucks reflect in extreme form how motorized transportation has successfully claimed - to the detriment of other modes of transportation - land use in North American cities and failed to protect vulnerable road users. Traditional traffic safety programs that deal with parental drivers at school entrances were quite beside the point at the ES school since such programs do not address nonparental truck traffic in the local streetscape.

In contrast, at the relatively middle class WS school, interviewed parents were especially worried about the chaos and congestion of the highly feminized traffic at the school entrance. On a daily basis, different forms of "intensive mothering" (Hays 1998) collided symbolically if not materially at peak drop off and pick up times. As drivers and nondrivers, parents negotiated the shared space of the school entrance to safeguard 
children's mobility and often conflicted with one another in their different mobility identities. Parents inhabited the contradictions of sometimes being a driver and other times being a pedestrian (or bicyclist) who seeks to protect children from motorized traffic. The prominent mothering culture of traffic safeguarding at the WS school was particularly apparent in the formalized traffic safety subcommittee, providing an example of how gender and social class intersect in specific carescapes.

This case study of parental traffic safeguarding demonstrates the intricate ways in which parents constitute automobility and resist it. It also illustrates the plurality of traffic safety culture and contestations between actors and the ways that such cultures are imbued with power at different scales of interaction (Moeckli and Lee 2007). Participants in our study revealed how local authorities privileged the automobility system and traffic flow to the detriment of parents and children and made parents primarily responsible for safeguarding children from motor vehicle traffic, whether nonparental or parental. This scenario, which depends on parents guarding children from traffic as part of invisible, highly gendered, domestic labour, upholds the illusion that automobility is safe. The actual dangers of automobility are largely obscured and political pressures to challenge this system are muted. When parents mobilized to protest inadequate traffic safety measures, local authorities were apt to discount their knowledge and experiences.

Our study only scratches the surface in exploring the social construction of parental narratives and practices about traffic safeguarding in relation to the economic, spatial, cultural, and discursive exigencies of their lives. Finely grained studies are needed to examine parental traffic safeguarding in a greater variety of geographical and social contexts to determine how it is embedded in the automobility system, how it serves as a foundation to the automotive city and a lynchpin to auto hegemony, and how it exacts large but hidden costs on parents and children.

The troubling effects of motorized streetscapes on parents and schoolchildren in this study suggest the significance of challenging auto hegemony and developing alternative urban and transportation discourses and planning. If we are to address car troubles (Conley and McLaren 2009), discourses need to be constructed from the bottom up to represent the interests of residential families with children rooted in daily experiences (Karsten 2009). If auto hegemony loosens its grip on transportation and urban design, parenting — especially mothering — may also be transformed, reducing its intense, worrisome, and unequal traffic safeguarding. 


\section{REFERENCES}

Adams, J. 1993. Risk compensation and the problem of measuring children's independent mobility and safety on the roads. Pp. 44-58 in M. Hillman, ed.,Child, Transport and Quality of Life. London: Policy Studies Institute.

Barker, J. 2011. "Manic mums" and "distant dads"? Gendered geographies of care and the journey to school. Health and Place 17(2):413-421.

BC Ministry of Education. 2009. School Data Summary Reports 2003/042007/08. Victoria BC: Ministry of Education.

Bean, C.E. et al. 2008. Exploring social mobilities: Narratives of walking and driving in Auckland, New Zealand. Urban Studies 45(13): 2829-2848.

Beckmann, J. 2004. Mobility and safety. Theory, Culture \& Society 21(4/5):81100.

City of Vancouver. 2002. Update on recent regional transportation data. Administrative Report. April 15. http://www.city.vancouver.bc.ca/ctyclerk/ cclerk/020430/a7.htm. (accessed November 22, 2007).

2009a. Communitywebpages. http://vancouver.ca/community_profiles/ communityList.htm. (accessed June 6, 2009).

2009b. Truck route map (updated Jan 2009).cdr. http://vancouver.ca/ engsvcs/transport/traffic/pdf/english map.pdf. (accessed March 12, 2010).

Collins, D. et al. 2009. "Mind that child": Childhood, traffic and walking in automobilized space. Pp. 127-143 in J. Conley and A.T. McLaren, eds., Car Troubles: Critical Studies of Automobility and Auto-Mobility. Farnham: Ashgate.

Collins, D.C.A. and R.A. Kearns. 2005. Geographies of inequality: Child pedestrian injury and walking school buses in Auckland, New Zealand. Social Science and Medicine 60(1):61-69.

Conley, J. and A.T. McLaren, eds. 2009. Car Troubles: Critical Studies of Automobility and Auto-Mobility. Farnham: Ashgate.

Delphy, C. and D. Leonard. 1992. Familiar Exploitation: A New Analysis of Marriage in Contemporary Western Societies. Oxford: Polity.

Desapriya, E. et al. 2011. Injury prevention in child death review: Child pedestrian fatalities. Injury Prevention 17(Suppl 1):i4-i9.

Dowling, R. 2000. Cultures of mothering and car use in suburban Sydney: A preliminary investigation. Geoforum 31(3):345-353.

Fox, B.J., ed. 2009. Family Patterns, Gender Relations, 3rd edition. Don Mills: Oxford University Press.

Freund, P.E.S. and G.T. Martin Jr. 1997. Speaking about accidents: The ideology of auto safety. Health 1(2):167-182. 
Griffith, A.I., and D.E. Smith. 1987. Constructing cultural knowledge: Mothering as discourse. Pp. 87-103 in J. Gaskell and A.T. McLaren, eds., Women and Education: A Canadian Perspective. Calgary, Alberta: Detselig Enterprises.

Hays, S. 1998. The Cultural Contradictions of Motherhood. New Haven, CT: Yale University Press.

Hillman, M. et al. 1990. One False Move...A Study of Children's Independent Mobility. London: Policy Studies Institute.

Jain, S.S.L. 2004. Dangerous instrumentality: The bystander as subject in automobility. Cultural Anthropology 19(1):61-94.

Jensen, O.B. 2009. Flows of meaning, cultures of movements: Urban mobility as meaningful everyday life practice. Mobilities 4(1):139-158.

Karsten, L. 2009. From a top-down to a bottom-up urban discourse: (Re) constructing the city in a family-inclusive way. Journal of Housing and the Built Environment 24:317-329.

Laflamme, L. et al. 2010. 20 years of research on socioeconomic inequality and children's - unintentional injuries understanding the cause-specific evidence at hand. International Journal of Pediatrics. Article ID 819687, 23 pages.

Lareau, A. 2003. Unequal Childhoods: Class, Race, and Family Life. Berkeley: University of California Press.

Law, R. 1999. Beyond "women and transport": Towards new geographies of gender and daily mobility. Progress in Human Geography 23(4):567588 .

Levine-Rasky, C. 2009. Dynamics of parent involvement at a multicultural school. British Journal of Sociology of Education 30(3):331-344.

Lord, S.E. et al. 2010. Vulnerability to pedestrian trauma: Demographic, temporal, societal, geographic, and environmental factors. British Columbia Medical Journal 52(3):136-143.

Lupton, D. 1999. Monsters in metal cocoons: 'Road rage' and cyborg bodies. Body \& Society 5(1):57-72.

MacGregor, D. 2002. Sugar bear in the hot zone: Understanding and interpreting the political basis of traffic safety. Pp. 125-142 in J.P. Rothe, ed., Driving Lessons: Exploring Systems that Make Traffic Safer. Edmonton: The University of Alberta Press.

Marshall, J.D. et al. 2009. Healthy neighborhoods: Walkability and air pollution. Environmental Health Perspectives 117(11):1752-1759.

Mayhew, D.R. et al. 2004. Heavy Trucks and Road Crashes. Ottawa: Traffic Injury Research Foundation.

McLaren, A.T. and S. Parusel. In press. Under the radar: Parental traffic safeguarding and automobility. Mobilities. 
McLean, A. 2010. "Real" men of the open road: Frontier White working-class masculinity and the Canadian trucking industry. Paper presented at the Canadian Sociological Association Meeting. Concordia University, Montréal, Québec, May 31.

McMillan, T.E. 2005. Urban form and a child's trip to school: The current literature and a framework for future research. Journal of Planning Literature 19(4):440-456.

Moeckli, J. and J.D. Lee. 2007. The making of driving cultures. Pp. 59-76 in Improving Traffic Safety Culture in the United States: The Journey Forward. Washington, DC: AAA Foundation for Traffic Safety.

Murray, L. 2008. Motherhood, risk and everyday mobilities. Pp. 47-63 in T.P. Uteng and T. Cresswell, eds., Gendered Mobilities. Aldershot: Ashgate.

Norton, P.D. 2008. Fighting Traffic: The Dawn of the Motor Age in the American City. Cambridge Mass.: The MIT Press.

Oliver, L. and D. Kohen. 2009. Neighbourhood income gradients in hospitalisations due to motor vehicle traffic incidents among Canadian children. Injury Prevention 15(3):163-9.

Parusel, S. and A.T. McLaren. 2010. Cars before kids: Automobility and the illusion of school traffic safety. Canadian Review of Sociology 47(2):129147.

Pooley, C.G. et al. 2005. The journey to school in Britain since the 1940s: Continuity and change Area 37(1):43-53.

Rajé. F. 2007. The lived experience of transport structure: An exploration of transport's role in people's lives. Mobilities 2(1):51-74.

Reay, D. 1998. Engendering social reproduction: Mothers in the educational marketplace. British Journal of Sociology of Education 19(2):195-209.

Ridgewell, C. et al. 2009. School travel modes: Factors influencing parental choice in four Brisbane schools. Urban Policy and Research 27(1):4357.

Roberts, H. et al. 1995. Children at Risk? Safety as a Social Value. Buckingham: Open University Press.

Rothe, J.P. 2002. Dispatchers and drivers: On-the-road economics and manufactured risk. Pp. 143-159 in J.P. Rothe, ed., Driving Lessons: Exploring Systems that Make Traffic Safer. Edmonton: The University of Alberta Press.

Safe Kids Canada. 2007. Child \& Youth Unintentional Injury: 10 Years in Review 1994-2003. https://www.safekidscanada.ca/enStore/tabid/59/CategoryID/1/List/1/Level/a/ProductID/80/language/en-CA/Default.aspx (accessed February 23, 2011).

Schuurman, N. et al. 2009. Pedestrian injury and the built environment: An environmental scan of hotspots. BMC Public Health 9:233 (1-10). 
Short, J.R. and L.M. Pinet-Peralta. 2010. No accident: Traffic and pedestrians in the modern city. Mobilities 5(1):41-59.

Skelton, C. 2010. Metro Vancouver's most dangerous intersections. Vancouver Sun September 11. http://maker.geocommons.com/maps/22280. (accessed September 11, 2010).

Sleet, D.A. et al. 2007. Traffic safety in the context of public health and medicine. Pp. 41-58 in Improving Traffic Safety Culture in the United States: The Journey Forward. Washington, DC: AAA Foundation for Traffic Safety.

Stanko, E.A. 1997. Safety talk: Conceptualizing women's risk assessment as a 'technology of the soul'. Theoretical Criminology 1(4):479-499.

Thomsen, T.U. 2005. Parents' construction of traffic safety: Children's independent mobility at risk? Pp. 11-28 in T.U. Thomsen et al., eds., Social Perspectives on Mobility. Aldershot: Ashgate.

Transport Canada. 2010. Canadian Motor Vehicle Collision Statistics: 2007. http://www.tc.gc.ca/eng/roadsafety/tp-tp3322-2007-1039.htm (accessed July 5, 2010).

Turcotte, M. 2008. Dependence on cars in urban neighbourhoods. Canadian Social Trends 85:20-30.

Urry, J. 2004. The 'system' of automobility. Theory, Culture \& Society 21(4/5):25-39.

Vannini, P. 2010. Mobile cultures: From the sociology of transportation to the study of mobilities. Sociology Compass 4(2):111-121.

Wegman, F. 2007. Road traffic in the Netherlands: Relatively safe but not safe enough! Pp. 281-304 in Improving Traffic Safety Culture in the United States: The Journey Forward. Washington, DC: AAA Foundation for Traffic Safety.

Arlene Tigar McLaren is Professor Emerita in the Department of Sociology and Anthropology at Simon Fraser University. Her research interests include gender, schooling, immigration, critical social policy, and automobility. She is a Research Affiliate with Metropolis BC and Research Associate of the Canadian Centre for Policy Alternatives.

mclaren@sfu.ca

Sylvia Parusel is a Ph.D. candidate in Sociology at Simon Fraser University. Sylvia's research interests include medicalization of addiction and poverty, women's studies and automobility studies.

sip@sfu.ca 